\title{
EFFECT OF GROUND GRANULATED BLAST FURNACE SLAG ON MECHANICAL BEHAVIOR OF PVA-ECC
}

Ing Lim

Department of Civil Engineering, National Taiwan University, Taipei, Taiwan, R.O.C., r96521250@ntu.edu.tw

Jenn-Chuan Chern

Department of Civil Engineering, National Taiwan University, Taipei, Taiwan, R.O.C.

Tony Liu

Department of Civil Engineering, National Taiwan University, Taipei, Taiwan, R.O.C.

Yin-Wen Chan

Department of Civil Engineering, National Taiwan University, Taipei, Taiwan, R.O.C.

Follow this and additional works at: https://jmstt.ntou.edu.tw/journal

Part of the Civil and Environmental Engineering Commons

\section{Recommended Citation}

Lim, Ing; Chern, Jenn-Chuan; Liu, Tony; and Chan, Yin-Wen (2012) "EFFECT OF GROUND GRANULATED BLAST

FURNACE SLAG ON MECHANICAL BEHAVIOR OF PVA-ECC," Journal of Marine Science and Technology. Vol. 20: Iss.

3, Article 11.

DOI: $10.51400 / 2709-6998.1810$

Available at: https://jmstt.ntou.edu.tw/journal/vol20/iss3/11

This Research Article is brought to you for free and open access by Journal of Marine Science and Technology. It has been accepted for inclusion in Journal of Marine Science and Technology by an authorized editor of Journal of Marine Science and Technology. 


\title{
EFFECT OF GROUND GRANULATED BLAST FURNACE SLAG ON MECHANICAL BEHAVIOR OF PVA-ECC
}

\author{
Ing Lim, Jenn-Chuan Chern, Tony Liu, and Yin-Wen Chan
}

Key words: cementitious composites, slag, ductility, toughness.

\begin{abstract}
As the most popular construction material, concrete has many advantages compared to other materials. However, its brittle nature causes cracking and results in many deterioration problems and failures in infrastructures. Considering the issue of sustainability, researchers around the world have conducted numerous studies to develop concrete that has better performances, higher durability, longer life span, and less damaging effects to nature. To obtain such characteristics, researchers not only focus on strength enhancement, but also ductility and toughness.

This paper examines the effect of using ground granulated blast furnace slag as partial cement replacement in producing engineered cementitious composite (ECC), a ductile cementitious composite reinforced with short random fibers. Slag replacement is not only to increase the strength but also to create better fiber bridging property that results in better ductility of the material. Amount of slag replacement and slag fineness are the variables involved in the mixture proportions. The mechanical behaviors of ECC under uniaxial tensile tests and flexural tests as parameters to measure its ductility are reported.
\end{abstract}

\section{INTRODUCTION}

Researches on concrete for ages created many types of special concrete with enhanced properties that lead to better performances in structural application and cause less damaging effect to nature in their production process. Compressive strength is a parameter that is generally considered as the most important in concrete. Thus researches had been carried out to create concrete with higher compressive strength that has also higher tensile strength, higher stiffness, and better durability. The only weakness of high strength concrete is that the higher

Paper submitted 02/24/11; revised 04/12/12; accepted 05/01/12. Author for correspondence: Ing Lim (e-mail: r96521250@ntu.edu.tw).

Department of Civil Engineering, National Taiwan University, Taipei, Taiwan, R.O.C. the strength is, the more brittle it is. But since not every failure mode is governed by the material strength property, it is necessary to also pay attention to the toughness and ductility of a material, especially for the structural elements in the seismic areas.

Concrete research was then developing toward the increase of toughness and ductility of the material by adding fibers into cementitious matrix. When cracks start to occur due to the applied stress on the specimen, fibers create bridging effect along the cracks and stop the cracks from propagating. Thus the material will not fail right away after first crack. Fibers are used either in short form to be randomly dispersed, or in continuous mesh form. Increasing the volume of fibers used in matrix may increase the ductile performance of the material. But for economic consideration and better properties in its early state, researchers, by micromechanics consideration, developed the engineered cementitious composites (ECC) that has the excellent ductility with low fiber fraction [4].

Taking sustainability into consideration, green ECC was then developed in order to create more sustainable material for sustainable infrastructure. To develop a new framework for green materials design, researches on the grain size distribution, micromechanics, and other parameters of some potential substitute materials, including cement replacement, sand replacement, and fiber replacement were conducted [3]. The goal was to develop engineered cementitious composites when the use of industrial waste is possible without sacrificing critical material properties. Preliminary evaluation result shows that the good potential substitutes are fly ash, cement kiln dust, and green foundry sand. In another research, green ECC was designed by replacing part of the cement with different types of fly ash and bottom ash, which have different calcium content and particle size [7, 10]. In Korea a research on ECC produced with ground granulated blast furnace slag has been accomplished [2]. This paper presents the study on the effect of ground granulated blast furnace slag on the mechanical properties of the ECC.

\section{ENGINEERED CEMENTITIOUS COMPOSITES}

Despite all the advantages of concrete that make it popular 


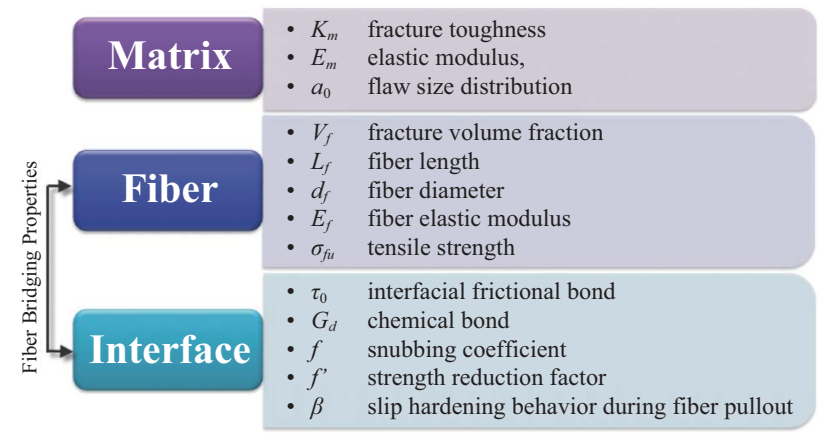

Fig. 1. Micromechanical parameters of ECC.

as building material, it is well known that concrete is a brittle material that has low resistance to tensile force. Fibers are used to cope with this drawback on conventional concrete. Fiber addition in fiber reinforced concrete (FRC) with moderate fiber volume fraction (one to two percent) is mainly to increase the modulus of rupture, fracture toughness, fatigue resistance, impact resistance, and other desirable mechanical properties. It has been widely applied both in cast-in-place and pre-cast structural members. Fiber added in high volume fraction (greater than two percent) is to gain the strengthhardening behavior of the composite. Fiber reinforced cementitious composite with high fiber volume fraction and strain-hardening behavior is called high performance fiber reinforced cementitious composite [9].

The multiple cracking in HPFRCC causes the material to have larger energy absorption capacity, larger strain capacity, higher ductility and toughness, thus it is potentially a good material for earthquake resistant structures. To achieve strainhardening response under tensile loading with multiple cracks in HPFRCC, large amounts of fibers are needed. Despite the advantages of HPFRCC, economic consideration together with the difficulties in processing had caused most of engineers to prefer to use regular FRC with strain softening behavior.

Since early 1990s researchers spent significant effort in developing a new kind of fiber cementitious composite that has strain-hardening response after first crack with low fiber volume fractions, which is below $2 \%$ so that its manufacturing by regular mixing process will be possible [8]. This was obtained by proper fiber selection and fiber treatment, and thorough micromechanics consideration to make the fibers work as effective as possible.

Engineered cementitious composite (ECC), a ductile mortar-based composite reinforced with low volume fraction of short random fibers, can be considered as the optimized HPFRCCs. Research and application then have been developing further for almost two decades, to gain the ductile composites behavior suitable for each application. Engineered cementitious composites are composed of two main constituents, i.e. fiber and matrix, which are mixed together and create bonding interface. The micromechanical parameters of ECC that characterize the fiber, matrix, and interface along with their notations are shown in Fig. 1. The interaction of
Table 1. Mixture proportions.

\begin{tabular}{|c|c|c|c|c|c|c|c|}
\hline Prop. & Cement & Slag & Water & Sand & MC & Defoamer & Fiber* \\
\hline C60 & 1.0 & 0.0 & 0.6 & 0.8 & 0.0015 & 0.00025 & 0.02 \\
\hline S2604 & 0.8 & 0.2 & 0.6 & 0.8 & 0.0015 & 0.00025 & 0.02 \\
\hline S2606 & 0.8 & 0.2 & 0.6 & 0.8 & 0.0015 & 0.00025 & 0.02 \\
\hline S4604 & 0.6 & 0.4 & 0.6 & 0.8 & 0.0015 & 0.00025 & 0.02 \\
\hline S4606 & 0.6 & 0.4 & 0.6 & 0.8 & 0.0015 & 0.00025 & 0.02 \\
\hline
\end{tabular}

* fiber volume fraction.

fiber and interface creates fiber bridging property, which is the most fundamental property of fiber reinforced cementitious materials [6]. Fiber bridging creates a toughening effect that leads to a process called steady-state cracking. For multiple cracking and pseudo strain-hardening to occur, steady-state cracking is absolutely required. The toughening effect will also increase the first crack strength of the composites.

The minimum limit of fiber content for pseudo strainhardening to occur is called critical fiber volume fraction, which is defined as below [5]:

$$
V_{f} \geq V_{f}^{c r i t} \equiv \frac{12 J_{c}}{g \tau\left(\frac{L_{f}}{d_{f}}\right) \delta_{0}}
$$

where $J_{c}$ is the matrix toughness, $\mathrm{g}$ is the snubbing factor, $\tau$ is the frictional bond strength between fiber and matrix, $L_{f} / d_{f}$ is aspect ratio, and $\delta_{0}$ is the corresponding crack opening. Based on the equation above, micromechanical design or tailoring on fiber and matrix to create most suitable interface for pseudo strain-hardening is necessary. Polymer fibers are usually preferable for small fiber diameter to achieve higher aspect ratio. Elastic modulus of the fiber plays a role on controlling crack width. High modulus of elasticity will come to use when the matrix cracking starts to occur. Fiber tensile strength determines the maximum bridging load, and fiber tensile strain capacity keeps the fiber to survive after matrix cracking and prevents fiber failure during mixing process. Chemical stability of the fiber (e.g., corrosion resistance, alkali resistance) is important for composite durability. Interface bonding needs to be designed very properly to gain the best composite response. Too low bonding stress causes fiber pullout before fiber bridging is formed, disusing the tensile capacity of the fiber; while too high bonding stress causes fiber rupture in the matrix with no slip hardening. These are the basis for controlling the properties of the composites for better performance.

\section{EXPERIMENTAL PROCEDURE}

Five mixture proportions were chosen, as shown in Table 1. For each proportion an index is given for the convenience of identifying the specimens by its mixture proportion. When the 
Table 2. Properties of Kuralon PVA fiber REC-15.

\begin{tabular}{|c|c|}
\hline$\sigma_{f u}$ & $1600 \mathrm{MPa}$ \\
\hline$L_{f}$ & $12 \mathrm{~mm}$ \\
\hline$\varepsilon$ & 0.06 \\
\hline$E_{f}$ & $40000 \mathrm{MPa}$ \\
\hline$d_{f}$ & $0.04 \mathrm{~mm}$ \\
\hline Application & mortar \\
\hline Specific gravity & 1.3 \\
\hline
\end{tabular}

Table 3. Grain distribution of refined sand No. 6.

\begin{tabular}{|c|c|c|}
\hline Sieve No. & $\mathrm{mm}$ & Amount retained (\%) \\
\hline 50 & 0.297 & 5.7 \\
\hline 70 & 0.210 & 30.6 \\
\hline 100 & 0.149 & 32.6 \\
\hline 140 & 0.105 & 20.4 \\
\hline 200 & 0.074 & 7.4 \\
\hline 270 & 0.053 & 2.6 \\
\hline PAN & & 0.7 \\
\hline
\end{tabular}

proportion contains no slag replacement, the index is started with letter $\mathrm{C}$ for cement and followed by two numbers of its water binder ratio in percentage. When the proportion contains slag replacement, the index is started with letter $\mathrm{S}$ for slag; the following number indicates the amount of slag replacement, 2 for $20 \%$ and 4 for $40 \%$; the next two numbers indicate the water-binder ratio; and the last number indicates slag fineness, 4 for slag grade 100 and 6 for slag grade 120, which fineness by air permeability test is around $4000 \mathrm{~m}^{2} / \mathrm{kg}$ and $6000 \mathrm{~m}^{2} / \mathrm{kg}$, respectively.

This experiment uses Kuralon fiber REC-15, polyvinyl alcohol (PVA) fiber manufactured by Kuraray Co., Ltd. of Japan. The fiber was treated with about $0.8 \%$ of oil coating agent to reduce the chemical bonding between fiber and matrix. The properties of REC-15 PVA fiver is provided in Table 2. The sand used in this experiment is silica sand No. 6 that passes $420 \mu \mathrm{m}$ sieves (No. 40), with $94.9 \%$ of $\mathrm{SiO}_{2}, 3.2 \%$ of $\mathrm{Al}_{2} \mathrm{SO}_{3}$, and $0.13 \%$ of $\mathrm{Fe}_{2} \mathrm{O}_{3}$. Grain size distribution is given in Table 3. Methylcellulose used in this experiment is WALOCEL ${ }^{\mathrm{TM}}$ MKX 45000 PF 20 L from Dow Chemical, in white powder form.

The mixture proportions are given in mass, except for the fiber that is given in volume fraction to mortar. At least 12 cylinder specimens for compression test and 34 plate specimens for tensile and flexural tests at three ages were prepared. Mixing process was started with dry mix. Sand, cement, and slag were mixed together with slow speed for about one minute. Then methylcellulose powder was added to the mixture and mixed again for another 30 seconds. Water mixed with defoamer was then slowly added while mixer was still running in low speed for about 2 minutes. Mixer speed then was increased to high speed for about 30 seconds and turned back to low speed while the remaining water was continued to be added slowly. The mixer was then stopped for about $30 \mathrm{sec}-$

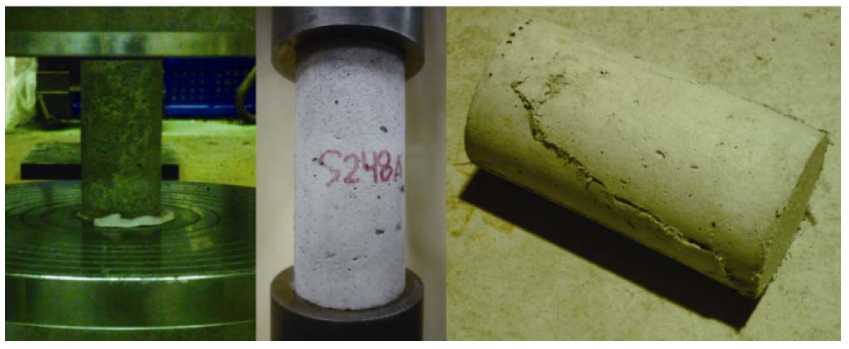

Fig. 2. ECC compression test.

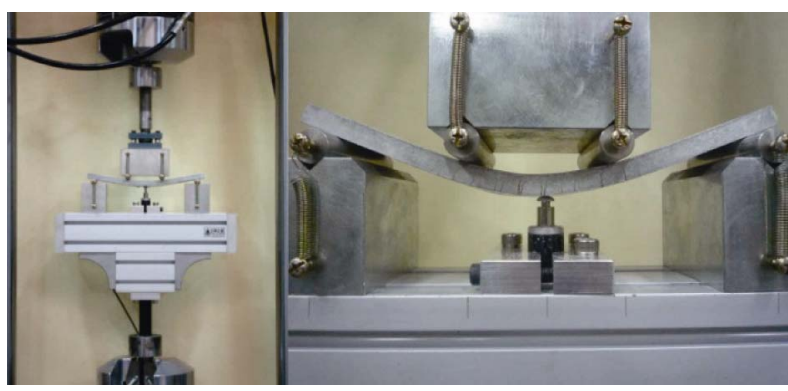

Fig. 3. ECC flexural test setup.

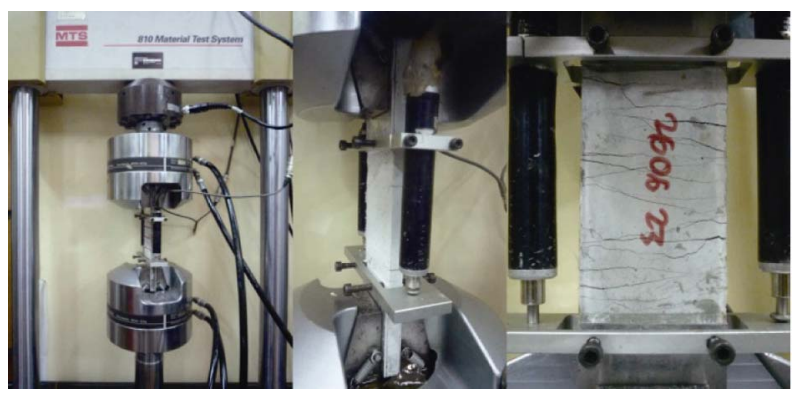

Fig. 4. ECC tensile test setup.

onds in order to scrape off the material that adhered to the bottom part of the mixing bowl with a metal rod and continued until the mixture seemed to be uniform. Then, still under low mixing speed, the polyvinyl alcohol (PVA) fiber was gradually added until all the materials were uniformly mixed. Casting was done on the normal frequency vibrating table, started with casting into the vertical mold. The process took about 30 minutes to one hour, due to the difficulties of casting mixture into the vertical mold.

In average, 4 compression specimens, 6 tensile specimens, and 3 flexural specimens were tested for each proportion at each age. The specimens were tested at the ages of 7 days, 28 days and 90 days. All the specimens were tested under displacement control. Testing setups are shown in Fig. 2 to Fig. 4.

\section{EXPERIMENTAL RESULTS AND DISCUSSIONS}

Amount of slag replacement, slag fineness, and the age of the specimens are the test parameters in this experiment. Nevertheless, there are many other factors that were not 
Table 4. Compressive strength and elastic modulus (MPa).

\begin{tabular}{|c|c|c|c|c|}
\hline \multirow{2}{*}{} & \multicolumn{3}{|c|}{ Compressive Strength } & \multirow{2}{*}{ E } \\
\cline { 2 - 4 } & 7 days & 28 days & 90 days & \\
\hline C60 & 24.41 & 31.61 & 36.38 & 13508.53 \\
\hline S2604 & 22.68 & 34.56 & 37.79 & 13398.27 \\
\hline S2606 & 25.64 & 35.78 & 41.07 & 14470.69 \\
\hline S4604 & 20.12 & 38.25 & 46.82 & \\
\hline S4606 & 25.18 & 45.37 & 49.57 & \\
\hline
\end{tabular}

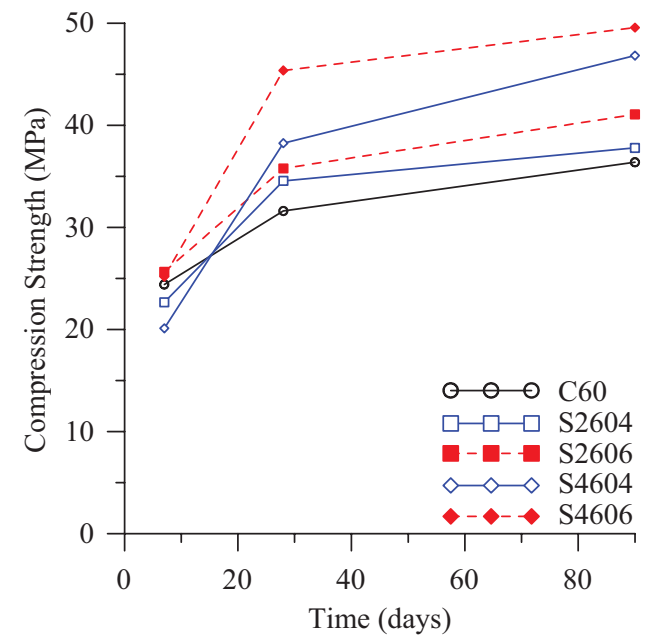

Fig. 5. Comparison of compressive strength development.

measured, e.g. bleeding rate, fiber dispersion, setting time, and compacting duration. Since the mixture contains fiber and was cast into $10 \mathrm{~mm}$ wide opening vertical mold, difficulties in casting caused longer casting time that was more than half an hour. During this period, there were some changes in the fresh state property of the material that caused some differences in the hardened state as well. Six to eleven specimens were cast in the same mold on the vibration table, causing each specimen to have different duration of vibration. In spite of these factors, experimental result is reported in accordance with the measurable properties.

\section{Compression Test}

Table 4 lists the compressive strength for each mixture proportion at three ages and the compressive strength development curves are shown in Fig. 5. Fig. 5 shows that mixtures containing slag generally increase compressive strength of the specimen, but slag grade 100 needs time for strength development so that the strength at early age might be lower. Early strength development was gained when slag grade 120 was used.

Calculation of modulus of elasticity in accordance with ASTM 469 [1] was done separately for each specimen of proportion C60, S2604, and S2606, and then the average value for each mixture proportion is reported. Table 4 contains the calculation results of chord modulus of elasticity. As expected,

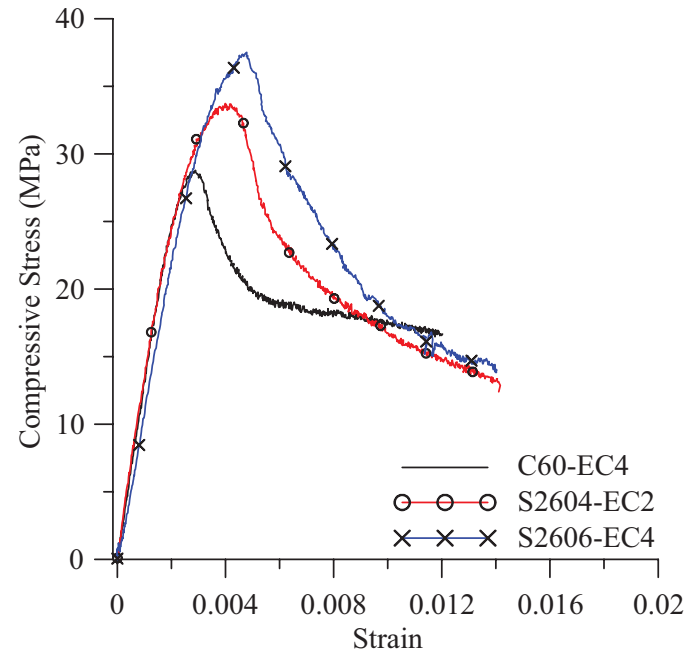

Fig. 6. Compressive stress-strain behavior of C60, S2604, and S2606.

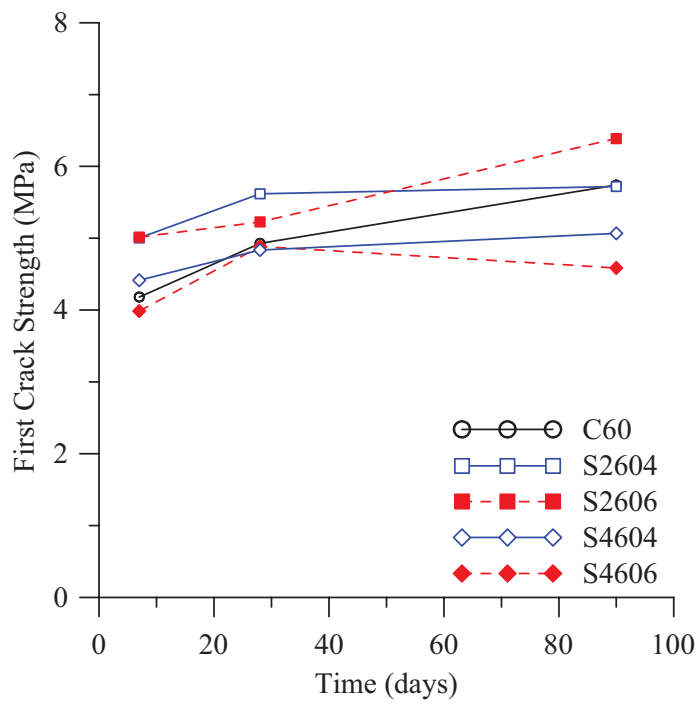

Fig. 7. First peak strength under flexural loading.

ECC has lower modulus of elasticity as compared to the conventional concrete with the same strength, due to the fact that ECC contains no coarse aggregate and the polymer fiber in ECC gives no contribution to its modulus of elasticity. Fig. 6 shows stress-strain curves from compressive test at 28 days of the three proportions.

\section{Flexural Test}

From all flexural specimens that were tested, two flexural curves were selected from each proportion at each age for analysis. Values of first peak load and maximum load are observed, along with the corresponding displacements. First peak strength was derived from the first peak load, which is the first point on the load-deflection curve where the slope is zero. The plots of the first crack strength at three ages are given in Fig. 7. 


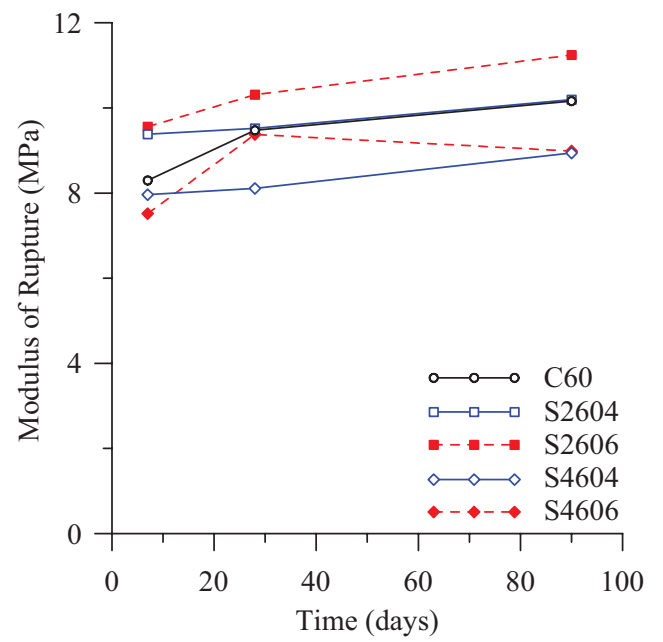

Fig. 8. Modulus of rupture.

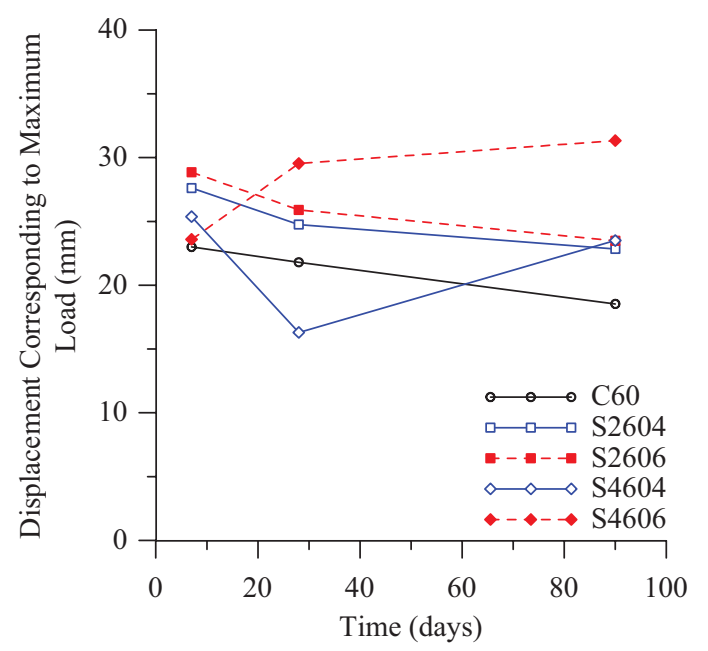

Fig. 9. Displacement corresponding to maximum load in flexural test.

Modulus of rupture denotes the flexural strength of a material. It is derived from the maximum flexural load a specimen could bear, which is observed from the flexural curve. The modulus of rupture of each mixture proportion at various ages of the specimen is shown in Fig. 8. For most of the specimens, the loading during flexural test kept increasing until near failure point. Thus the displacement corresponding to maximum load, as shown in Fig. 9, can be considered as the indication of ductility of the material.

\section{Tensile Test}

There are three critical points that are chosen, which are the point when first crack occurred, the point when tensile load reached maximum value, and the last point when the slope is zero, which is considered as its displacement capacity. The load in $\mathrm{kN}$ unit was converted to strength in MPa unit by dividing the load value with sectional area of the specimen. Two specimens were selected from each proportion at each age.

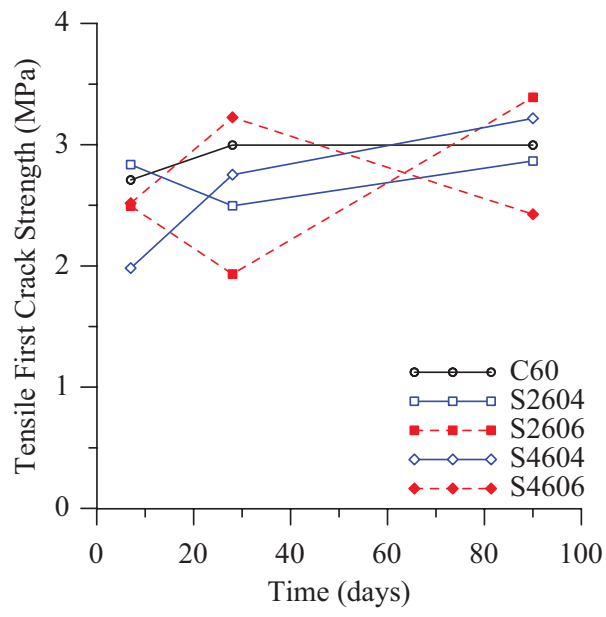

Fig. 10. First crack strength under tensile loading.

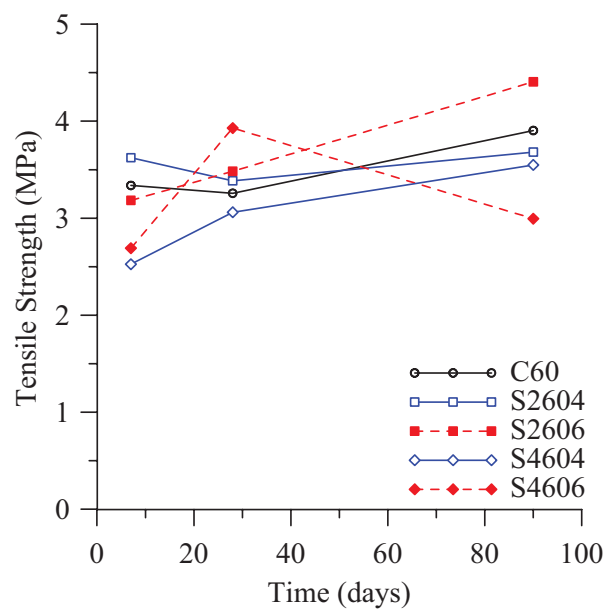

Fig. 11. Tensile strength.

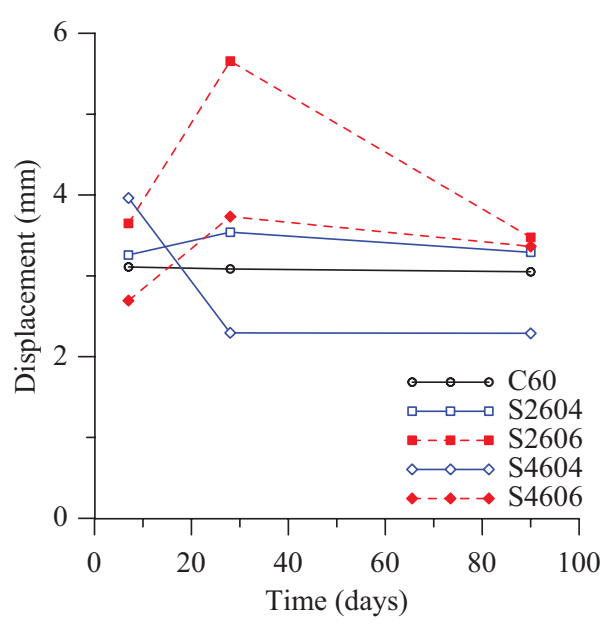

Fig. 12. Displacement capacity under tensile loading.

The first crack strength, tensile strength, and displacement capacity at the given age of the specimen for each mixture proportion are given in Fig. 10 to Fig. 12, respectively. 


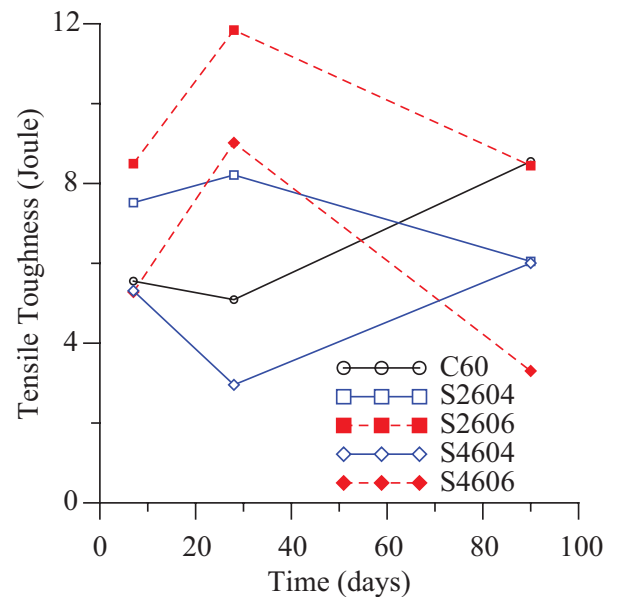

Fig. 13. Comparison of toughness obtained from tensile test.

Toughness is calculated as the area below tensile loaddisplacement curve up to the last strain hardening occurred, as measure of energy in unit Joule. One curve is selected for each proportion for toughness calculation. The tensile toughness of each mixture proportion is shown in Fig. 13.

\section{CONCLUSION}

A series of experiment to study the effect of ground granulated blast furnace slag on mechanical behavior of engineered cementitious composites produced with polyvinyl alcohol fiber had been carried out. Observation was made on compressive, tensile, and flexural tests. The compressive strengths at various ages and elastic moduli at 28 days from compressive tests were reported. From flexural tests, first peak load, modulus of rupture, and displacement corresponding to the maximum load were reported. From tensile tests, first crack strength, tensile strength, displacement capacity, and tensile toughness were reported. This study concluded that the effect of ground granulate blast furnace slag replacement not only increased the strength but also created a better fiber bridging property that resulted in better ductility of the ECC.

\section{REFERENCES}

1. ASTM Standard C469-02, "Standard test method for static modulus of elasticity and Poisson's ratio of concrete in compression," American Society for Testing and Materials, West Conshohocken, Pennsylvania (2001).

2. Kim, Y. Y., Kim, J. S., Ha, G. J., and Kim, J. K., "ECC produced with granulated blast furnace slag" (2009).

3. Lepech, M. D., Li, V. C., Robertson, R. E., and Keoleian, G. A., "Design of green engineered cementitious composites for improved sustainablity," ACI Materials Journal, Vol. 105, No. 6, pp. 567-575 (2008).

4. Li, V. C., "Engineered cementitious composites (ECC) - tailored composites through micromechanical modeling," Fiber Reinforced Concrete: Present and the Future, pp. 64-97 (1998).

5. Li, V. C., "Large volume, high-performance applications of fibers in civil engineering," Journal of Applied Polymer Science, Vol. 83, pp. 660-686 (2002).

6. Li, V. C., "On engineered cementitious composites (ECC)," Journal of Advanced Concrete Technology, Vol. 1, No. 3, pp. 215-230 (2003).

7. Li, V. C., Lepech, M., Wang, S., Weimann, M., and Keoleian, G., "Development of green engineered cementitious composites for sustainable infrastructure systems," Proceedings of the International Workshop on Sustainable Development and Concrete Technology, Beijing, pp. 181-191 (2004).

8. Li, V. C., Mishra, D. K., and Wu, H. C., "Matrix design for pseudo strainhardening fiber reinforced cementitious composites," RILEM Journal of Materials and Structures, Vol. 28, No. 183, pp. 586-595 (1995).

9. Mehta, P. K. and Monteiro, P. J. M., Concrete Microstructure, Properties, and Materials, 3rd Edition, McGraw-Hill, New York (2006).

10. Wang, S. and Li, V. C., "Engineered cementitious composites with highvollume fly ash," ACI Materials Journal, Vol. 104, No. 3, pp. 233-241 (2007). 